Hope College

Hope College Digital Commons

Faculty Publications

6-26-2018

\title{
A Model of Motor and Sensory Axon Activation in the Median Nerve Using Surface Electrical Stimulation
}

Jessica L. Gaines

Kathleen E. Finn

Julia P. Slopsema

Lane A. Heyboer

Katharine H. Polasek

HopeCollege,polasek@hope.edu

Follow this and additional works at: https://digitalcommons.hope.edu/faculty_publications

Part of the Biomedical Engineering and Bioengineering Commons

\section{Recommended Citation}

Repository citation: Gaines, Jessica L.; Finn, Kathleen E.; Slopsema, Julia P.; Heyboer, Lane A.; and Polasek, Katharine H., "A Model of Motor and Sensory Axon Activation in the Median Nerve Using Surface Electrical Stimulation" (2018). Faculty Publications. Paper 1447.

https://digitalcommons.hope.edu/faculty_publications/1447

Published in: Journal of Computational Neuroscience, Volume 45, Issue 1, June 26, 2018, pages 29-43. Copyright (c) 2018 Springer US.

This Article is brought to you for free and open access by Hope College Digital Commons. It has been accepted for inclusion in Faculty Publications by an authorized administrator of Hope College Digital Commons. For more information, please contact digitalcommons@hope.edu. 


\section{A Model of Motor and Sensory Axon Activation in the Median Nerve Using Surface Electrical Stimulation}

Jessica L. Gaines, Hope College, ilgaines2@gmail.com

Kathleen E. Finn, Hope College, kathleen.finn@hope.edu

Julia P. Slopsema, University of Minnesota, slops001@umn.edu

Lane A. Heyboer MS, Hope College, lane.heyboer@gmail.com

Katharine H. Polasek PhD, Hope College, polasek@hope.edu

Correspondence to:

Katharine H. Polasek, Ph.D.

Associate Professor of Engineering

Hope College

223F Vanderwerf

27 Graves Place

Holland, MI 49423

polasek@hope.edu

ORCID: 0000-0003-4317-8899

Phone: $616-395-7079$

Fax: $\underline{616-395-7123}$

Acknowledgments: The authors would like to express appreciation to Matthew Schiefer for his assistance in using Ansys and general modeling advice.

Funding was received from the following entities but none of these entities had any role in design of the study or analysis of the data.

- Hope College Dean of Natural and Applied Sciences

- A grant to 'Hope College' from the Howard Hughes Medical Institute through the Precollege and Undergraduate Science Education Program.

- Michigan Space Grant Consortium Undergraduate Fellowship Program

- Hope College Nyenhuis Faculty Development Fund 


\begin{abstract}
Surface electrical stimulation has the potential to be a powerful and non-invasive treatment for a variety of medical conditions but currently it is difficult to obtain consistent evoked responses. A viable clinical system must be able to adapt to variations in individuals to produce repeatable results. To more fully study the effect of these variations without performing exhaustive testing on human subjects, a system of computer models was created to predict motor and sensory axon activation in the median nerve due to surface electrical stimulation at the elbow. An anatomically-based finite element model of the arm was built to accurately predict voltages resulting from surface electrical stimulation. In addition, two axon models were developed based on previously published models to incorporate physiological differences between sensory and motor axons. This resulted in axon models that could reproduce experimental results for conduction velocity, strength-duration curves and activation threshold. Differences in experimentally obtained action potential shape between the motor and sensory axons were reflected in the models. The models predicted a lower threshold for sensory axons than motor axons of the same diameter, allowing a range of sensory axons to be activated before any motor axons. This system of models will be a useful tool for development of surface electrical stimulation as a method to target specific neural functions.
\end{abstract}

Keywords - Axon model; Motor axon model; Sensory axon model; Finite element model; Surface electrical stimulation 


\section{INTRODUCTION}

Surface electrical stimulation has the potential to be a powerful and non-invasive treatment for a variety of medical conditions. Electrical stimulation in general is used to promote plasticity and recovery of voluntary movements in individuals with spinal cord injury (Angeli et al. 2014) and stroke (Peurala et al. 2002; Walker et al. 2014).

Treatments involving electrical stimulation are also being developed for conditions such as diabetes, asthma, hypertension, arthritis, pain and cancer (Birmingham et al. 2014). Surface electrical stimulation as a method to target specific neural functions would make such treatments more accessible and acceptable to patients.

Consistent responses are difficult to obtain using surface electrical stimulation due to variable electrode placement, skin movement and physiological variables that affect tissue conductance. A viable clinical system must be able to adapt to these variations to produce repeatable results. To more fully study the effect of these variations without performing exhaustive testing on human subjects, a set of computer models were developed. The models will facilitate prediction of the effect of different variables such as size, shape and location of electrodes on axon activation. Initially it will be used to develop an electrode array to be used in a therapy for treating phantom limb pain. The therapy will involve activating sensation by stimulating the median nerve at the elbow. This paper presents a set of models to predict the behavior of this application. The models were based on previous models published in literature (Howells et al. 2012; C. McIntyre et al. 2002; Schiefer et al. 2008) and validated with experimental data.

Modeling the activation of neurons using electrical stimulation involves performing two separate sets of calculations (Goffredo et al. 2014): 1) find the electric potentials due to the applied stimulation and 2) determine the effect of those potentials on the neuron (i.e. does it fire or not). Early modeling studies estimated potentials along the nerve due to a point source electrode in a homogeneous, isotropic medium near the nerve (W. Grill and Mortimer 1997; Warman et al. 1992). This method assumed that the electrode was sufficiently close to the axons that the extracellular space could be assumed to be homogenous. When the electrode is farther from the axon, this assumption becomes less accurate. Finite element modeling has been used to include 
the tissue layers around the electrodes and nerve, each layer with distinct electrical properties. A simplified FE model of the arm that consisted of concentric cylinders of bone, muscle, fat and skin has been used predict responses due to transcutaneous electrical stimulation (Goffredo et al. 2014; Kuhn et al. 2009). However, this level of detail was not sufficient for the investigation of varying electrode arrangements. Schiefer et al developed a more detailed finite element model of extraneural stimulation that used actual human nerve cross sections to define the geometry (Schiefer et al. 2008). This model included an accurate rendition of the electrode as well as detailed neural features, such as the perineurim and epineurium. The purpose of the current study was to create a more detailed, whole-arm model that will allow investigation of changes in electrode position/arrangement.

There are many reported differences between motor and sensory axons, such as the fact that sensory axons have a lower threshold, a slightly higher conduction velocity and different recovery than motor axons (Dawson 1956; Forst et al. 2015; Kiernan et al. 1996). This study focused on the median nerve, which contains both motor and sensory fibers, so it was important to take into account these differences when predicting activation. These differences have been reported to be due to disparities in the properties of ion channels in the membrane (Bostock and Rothwell 1997; Howells et al. 2012). Many groups have developed individual motor or sensory models (Bostock et al. 1991; C. McIntyre et al. 2002; Wesselink et al. 1999), but in order to compare activation between the two types of axons, the models needed to be developed in concert, as was done by Howells et al (Howells model).

The Howells models included a single node and internode, similar to what is accessed during a space-clamped measurement. This allowed parameter development based on experimental results but cannot be used with voltages from the larger arm model. This model focused on the hyperpolarization-activated cyclic-nucleotide-gated ( $\mathrm{HCN}$ ) family of channels but also included different types of sodium and potassium channels at the node than in the internodal segments. In comparing motor and sensory axons, this study found that differences in channel gating parameters were at least as important as channel expression differences in explaining excitability differences (Howells et al. 2012). 
A double-cable mammalian motor axon model developed by McIntyre, Richardson and Grill (MRG model) (C. Mclntyre et al. 2002) used the voltages along the axon to predict activation and therefore could be used with the larger arm model. The MRG model has been used for neural predictions in a variety of applications such as peripheral nerve activation (Peterson et al. 2011; Schiefer et al. 2008; Wongsarnpigoon et al. 2010), high frequency stimulation (Kilgore and Bhadra 2004; Medina and Grill 2016; Miles et al. 2007), and cortical activation (C. C. Mclntyre and Grill 2002).

In this study, the benefits of these two models were combined; the MRG model was used as the foundation of a full axon model, and was modified to include ion channels used by Howells in the node and internode to produce new sensory and motor axon models. These models in combination with the whole arm model, could predict responses from surface electrical stimulation. The goal of this study was to verify model predictions with previously published experimental data to allow future investigation of variations in electrode arrangement.

\section{METHODS}

To fully model surface electrical stimulation, three models were developed. The first was a 3-dimensional, anatomically-based finite element method (FEM) model of the arm that included electrodes near the elbow and electrical properties for each tissue domain. This arm model was used to predict voltages in throughout the fascicles within the median nerve. The voltages were then applied to an axon model, which was created and run in NEURON (v7.3, (Hines and Carnevale 1997)) to predict whether or not a sensory or motor axon would fire in that particular location. Simulations were performed to predict what percentage of each type of axon were activated using different stimulation voltages and these results were validated with experimental data.

\subsection{Arm Model}

Cross sections of the human arm were needed to represent the 3D structures of the arm. Simplified cross sections of the arm near the elbow were used that included the humerus, radius and ulna as well as muscles, blood vessels and nerves (Fig. 1) ("Elbow Cross Sectional Anatomy" 2014). Increasing the number of cross sections greatly 
increased the complexity and solution time of the model so only two cross sections were used, one located at the elbow's synovial hinge joint and one $20 \mathrm{~mm}$ proximal to the joint. These locations were chosen to adequately represent the anatomy at the area where the electrodes were placed. The cross sections were traced using Creo Parametric (formerly Pro-Engineer from PTC, Akron, $\mathrm{OH}$ ) then each tissue was swept along a trajectory between the two cross-sections placed $20 \mathrm{~mm}$ apart. The ends were extruded $300 \mathrm{~mm}$ in each direction to minimize edge effects and approximately represent the length of the arm (Drillis et al. 1964).

The three dimensional assembly was imported into Maxwell 2014 (ANSYS, Canonsburg, Pennsylvania). Conductivity values were assigned to each tissue (Table 1). Two electrodes (17mm $\times 45 \mathrm{~mm}$ ) were placed on the center of the arm to match experimental positioning (Forst et al. 2015) (Fig. 1).

TABLE 1

\begin{tabular}{|c|c|}
\hline ELECTRICAL & IES OF TISSUES \\
\hline Material & Conductivity ( $\mathrm{S} / \mathrm{m})$ \\
\hline Epineurium & $0.083^{a}$ \\
\hline Perineurium & $0.002^{a, d}$ \\
\hline $\begin{array}{l}\text { Endoneurium } \\
\text { (longitudinal) }\end{array}$ & $0.57^{\mathrm{a}, \mathrm{e}}$ \\
\hline $\begin{array}{l}\text { Endoneurium } \\
\text { (transverse) }\end{array}$ & $0.08^{a, e}$ \\
\hline Blood & $0.606^{b}$ \\
\hline Bone & $0.02^{\mathrm{c}}$ \\
\hline Fat & $0.0303^{c}$ \\
\hline Muscle (longitudinal) & $0.33^{c}$ \\
\hline Muscle (transverse) & $0.11^{\mathrm{c}}$ \\
\hline Skin & $0.0014^{c}$ \\
\hline Tendon & $0.06^{f}$ \\
\hline
\end{tabular}

${ }^{\mathrm{a}}$ (Choi et al. 2001), b(Geddes and Baker 1967), ' (Kuhn et al. 2009),

${ }^{d}$ (Weerasuriya et al. 1984), ${ }^{e}$ (Ranck and BeMent 1965), ${ }^{f}($ Dimbylow 2000)

There were four versions of the model, varying only in the anatomy of the median nerve. The first had a simplified nerve with a single fascicle (Fig. 2A) and was used to test parameters of the motor and sensory axon models as described below. The other three versions contained a random arrangement of fascicles, created to account for 
variations in human anatomy. The number of fascicles in a median nerve according to histological data ranges from 3 to 37 , varying with location along the arm and among people (Sunderland 1978). For this study, ten fascicles were used. The fascicle diameters were based on measurements of a human median nerve cross-section at the elbow and ranged in diameter between $0.264 \mathrm{~mm}$ and $0.800 \mathrm{~mm}$ (Suresh et al. 2006). For each fascicle, the thickness of the perineurium was set to three percent of the fascicle diameter (Grinberg et al. 2008).

Stimulation was applied by setting the cathode (proximal electrode) to $-1 \mathrm{~V}$ and the anode to $1 \mathrm{~V}$. The boundary conditions of the ends of the model were set as ground (Schiefer et al. 2008). Frequency-independent simulations were performed using the DC Conduction solver in Ansys Maxwell. Auto-adaptive mesh refinement was used to generate a final mesh with a percent error in the voltage field of less than $0.05 \%$. The voltages in the nerve along the length of the arm were exported to MATLAB R2013a (Mathworks, Natick MA) with a $0.05 \mathrm{~mm}$ resolution in the $x-y$ directions and a $0.667 \mathrm{~mm}$ resolution in the $z$ direction along the nerve (Fig. 1). The voltage changed smoothly throughout a single tissue so a lower resolution could be used along the nerve ( $z$ direction). In the X-Y plane, the largest error occurred with axons located near the edge of a fascicle and interpolation was performed between a point inside and outside the fascicle. For this reason, axons were not placed within one resolution distance from the edge of a fascicle (or $0.05 \mathrm{~mm}$ ). This resolution resulted in 6 points across the smallest fascicle and 17 points across the largest fascicle.

\subsection{Axon Models}

To predict the activation of sensory axons and address the differences between motor and sensory axons, new axon models were developed. The new models were based on a motor axon model (MRG model) (C. Mclntyre et al. 2002) and created in the NEURON programming environment (Hines and Carnevale 1997). The MRG model was a double-cable model consisting of nodes separated by internodal segments coated in myelin. The internode was divided into ten segments: two paranodal myelin attachment segments (MYSA); two paranodal main segments (FLUT); and six internodal segments (STIN) (Fig. 3A). The major changes between the MRG model and 
the new models were the inclusion of a fast $\mathrm{K}^{+}$channel in the node and the addition of several channels in the internode as suggested by the Howells model (Howells et al. 2012). The MRG model lumped all internodal channels into a single conductance. The models developed here included fast $\mathrm{K}^{+}$, slow $\mathrm{K}^{+}$, leak, and hyperpolarization-activated cyclic-nucleotide gated (HCN) channels in the internode (Fig. 3B).

For the motor axon model, parameters used in the MRG model were retained when possible. Gating parameters from the Howells model were used to add $\mathrm{HCN}$ channel to the new model. The fast $\mathrm{K}^{+}$conductance in the node was found using the ratio of fast to slow potassium channels found in the Howells model. Ratios of the conductance of fast $\mathrm{K}^{+}$, slow $\mathrm{K}^{+}$, and leak between the node and internode reported by Röper and Schwarz (Roper and Schwarz 1989) were used to estimate the conductance values of the internode; however, the ratio between leak conductance of MYSA and that of FLUT and STIN was maintained from the MRG model. Reversal potentials were made to match the MRG model where possible. For the HCN channel, reversal potentials were calculated using the Goldman-Hodgkin-Katz equation using the concentrations and permeabilities reported in Howells.

The revised motor axon model was used as a foundation for the development of a sensory axon model. Each of the values used to calculate the gating parameters was converted from motor to sensory using the ratio found between these channels in the models by Howells (Howells et al. 2012). When possible, the internodal conductance values were derived using the ratios of internodal to nodal values found in Röper and Schwarz (Roper and Schwarz 1989). The ratio between the leak conductance of MYSA and that of FLUT and STIN was maintained from the MRG model. A value for the conductance per unit area of the HCN channel could not be found in literature for motor or sensory axons, so a range of values were tested, maintaining the motor-to-sensory ratio between the HCN absolute conductance values found in the Howells model. The values chosen were found to result in steady-state voltages close to the resting potentials given by the Howells model. At completion, the resting potential was -85.91 $\mathrm{mV}$ for the motor axon model and $-79.37 \mathrm{mV}$ for the sensory axon model compared to $-84.4 \mathrm{mV}$ and $-80.3 \mathrm{mV}$ from the Howells model. A table of parameter values can be found in Appendix B. 
Validation of both axon models was performed using simulations of one axon centered in the single fascicle nerve model (Fig. 2A). This reduced the variability that would have resulted from randomizing axon location. Conduction velocity, action potential shape, and the strength-duration relationship were used to evaluate the model. A sensitivity analysis was conducted to determine the relative effects of each conductance parameter on the activation threshold. A fractional factorial design of type $2 \mathrm{IV}^{11-6}$ was used to separate the main effects of each parameter from the effects due to two-factor interactions. This involved 11 factors with two levels each and would require 2048 observations to do a full factorial design. The fractional design made it impossible to distinguish interactions of 3-factors or more but provided a statistical comparison of sensitivity with only 32 observations. The activation threshold was found with parameter combinations at two levels: the nominal value and double the nominal value. These thresholds were analyzed to determine the main effects of each parameter and all twofactor interaction effects. The tests were repeated with the parameters at the nominal value and half of the nominal value. While not ideal, this allowed a further exploration of the sensitivity of the model to decreasing the parameters without the nearly 200,000 observations required for a three level, 11 factor, factorial design.

\subsection{Simulation details}

The calculated voltages within the more realistic ten fascicular nerves (Fig. 2C-E) were used to predict firing using the validated motor and sensory axon models. An axon length of 160 nodes ( 130 distal to the center of the cathode and 30 proximal) was found to accurately reproduce the results of using the full $620 \mathrm{~mm}$ length. Axons were randomly placed within each fascicle leaving $0.05 \mathrm{~mm}$ between the placement and the edge of the fascicle to avoid interpolation involving points in the perineurium. The diameter of axons was assigned randomly based on the reported distribution of diameters in the median nerve at the elbow (Fig. 4) (Buchthal and Rosenfalck 1966). Additionally, $15 \%$ of the 250 axons within each fascicle were randomly designated as motor axons. This is based on reports that $33 \%$ of axons in the median nerve were traced to muscles (Sunderland 1978 ) and $40 \%-60 \%$ of this $33 \%$ were estimated to be 
efferent, motor axons (lan A Boyd and Davey 1968; Feinstein et al. 1955). A pulse duration of $100 \mu$ s was used for all trials while the pulse amplitude was varied.

To find the whole nerve activation, the percent activation in each fascicle was weighted by the area and summed. This nerve activation was averaged across all three multi-fascicular versions of the model to compare motor and sensory axon activation and activation by diameter. To compare activation across the nerve, activation was averaged across all axon diameters and both axon types for each fascicle.

Statistical analysis was performed using $\mathrm{R}$ to quantify the effect of voltage, axon diameter, axon type, fascicular diameter and distance from the electrode on percent activation. After finding valid linear relationships, two linear regressions were performed. The first predicted percent activation of the entire nerve based on voltage, axon diameter, and axon type. The second predicted percent activation of a fascicle based on voltage, distance from the electrode, and fascicle diameter. Each regression was used to evaluate overall effectiveness by using the $R^{2}$ value, statistical significance of each factor by using an ANOVA test, and the presence of multi-variable interaction effects.

\section{RESULTS}

The Maxwell arm model with the single fascicular nerve had 641,949 tetrahedra and required 5 hours to calculate the solution on a Windows 8.1 computer with a quad core, 3.4GHz processor. With the multi-fascicular nerve, there were 3,402,877 tetrahedra and 9 hours were required to calculate the solution. The NEURON models required about 40 seconds per axon to determine if that axon was activated for each location within the nerve and stimulation voltage.

\subsection{Single Axon Model}

\subsubsection{Threshold Comparison}

With the added channels and modified parameters, the sensory axon model predicted a lower threshold for a given fiber diameter than the motor axon model, as seen in Fig. 5. The shape of both curves is consistent with the fact that larger axons have a lower threshold. Additionally, the model predicted that sensory axons as small as $12 \mu \mathrm{m}$ could be activated at a lower voltage than $16 \mu \mathrm{m}$ diameter motor axons in the 
same position. This would explain why sensations in the hand were reported without visible muscle contraction (Forst et al. 2015).

\section{$\underline{3.1 .2 \text { Validation }}$}

Conduction velocity, strength-duration curves, and action potential shape from the new models matched experimental results reported in the literature. Conduction velocity was found to have a linear relationship with fiber diameter (Fig. 6). The slope of this relationship and the range of values from the models matched the experimental range measured in cats when adjusted for shrinkage of the experimental data (I A Boyd and Kalu 1979). Additionally, the conduction velocities predicted by the models for motor axons were slightly higher than sensory axons for a given fiber diameter, which is consistent with human experimental data (Dawson 1956).

Strength-duration curves from both sensory and motor axon models compared well with curves measured from human median and ulnar nerves (Panizza et al. 1994) for sensory and motor axons. When normalized to the rheobase voltage, the model data had a similar shape to curves produced experimentally for each type of axon (Fig. 7). For the $10 \mu \mathrm{m}$ fiber, the sensory axon model had a rheobase of $6.2 \mathrm{~V}$ and a chronaxie of $0.23 \mathrm{~ms}$. The motor axon model had a rheobase of $14.2 \mathrm{~V}$ and a chronaxie of $0.15 \mathrm{~ms}$.

Differences were found between the shapes of the motor and sensory action potentials (Fig. 8) that matched differences seen in experimental recordings (David et al. 1995; Stebbing et al. 1999). The sensory model contained a much larger early hyperpolarization than motor that then rose gradually back to resting potential. The membrane voltage in the motor model instead stayed above resting potential immediately following the action potential, before it gradually decreased into hyperpolarization. The action potential also had a slightly longer duration in the motor model than the sensory, which was also found in the experimental voltage traces.

Although the simulated action potentials had a similar shape to experimental recordings, there were some differences in the timing of the action potential and the magnitude of the voltage fluctuations, especially during the afterpotential. The voltage during the afterpotential did go through periods of hyperpolarization and depolarization but this phase had a shorter duration and lower magnitude than seen experimentally. 
The model action potentials were also narrower than the experimental recordings for both types of axons. The width of the action potential of the motor axon model was similar to that of the original MRG model but again there were differences in the timing and voltage magnitude during the afterpotential.

\subsubsection{Sensitivity Analysis}

A sensitivity analysis was used to rank the importance of the contribution of each channel conductance to the activation threshold of the axon models (detailed list of parameters in Fig. 9). The difference between the average threshold of trials when each parameter was at double its nominal value and at its nominal value is shown in Fig. 9. Only the main effects are shown since the two-factor interactions were extremely small when compared with the main effects $(<0.6 \mathrm{~V}$ or $<3.3 \%$ of threshold) and were considered negligible. The parameter with the largest effect on threshold was the fast sodium channel conductance (E in Fig. 9) followed by the conductance of the HCN channel and leak conductance (the top five contributors are bolded in the legend). The analysis of the parameters at the nominal values and half of the nominal values yielded similar results with the same top-five contributors. The details of the justification for the values chosen for these five parameters are in the discussion.

\subsection{Whole Nerve Activation}

The actual distribution of axon diameters that resulted from the random assignment of axon diameters followed the intended distribution (data points in Figure 4). When the new axon models were used in the 10 fascicular nerves, sensory axons were again found to have a lower threshold than motor axons. For example, at $25 \mathrm{~V}$, an average of $37 \%$ of sensory axons in the nerve were activated, while an average of $3 \%$ of motor axons were activated (Fig. 10A). This is consistent with experimental results where sensory percepts could be evoked without visible muscle contraction (Forst et al. 2015; Veale et al. 1973). Pulse amplitudes up to $50 \mathrm{~V}$ were tested to be consistent with experimental protocol but both sensory and motor activation would reach $100 \%$ using higher voltages. Additionally, smaller diameters required a higher voltage to activate than larger diameters (Fig. 10B), as expected (W. M. Grill 2004). Since these data were averaged across all axons in the nerve, smaller axons in closer fascicles could be 
activated prior to larger axons in further fascicles. For example at $20 \mathrm{~V}, 27 \%$ of the $12 \mu \mathrm{m}$ axons were activated while $83 \%$ of the $14 \mu \mathrm{m}$ axons were activated.

At lower voltages, more axons in fascicles closest to the electrodes were activated than in the further fascicles as expected (Fig. 11A). In each nerve cross-section, there were three discrete groups of fascicles that had similar activation patterns (Fig. 11B). This suggests that selectivity by a small group of fascicles is possible using surface electrical stimulation and supports reports of sensation in small portions of the hand without muscle contraction (Forst et al. 2015).

Linear regression models were created to predict percent activation of the nerve and percent activation of a fascicle based on the input variables of stimulation voltage, axon or fascicle diameter, axon type and distance from the electrode. The regression models were also used to determine which variables had significant contribution to the overall activation. These linear regression models were able to explain between 80 and $93 \%$ of the variability in the data.

Predictions of whole nerve activation with a linear regression model were only able to explain $84 \%$ of the variability. This level of accuracy was obtained by the inclusion of all two and three way interactions. The regression model found that the input variables of axon diameter, stimulation voltage and type of axon (sensory or motor) were all significant contributors $(p<0.01$ ), as would be expected from our understanding of the system. However, given the accuracy of the regression model, it could not be used to replace the simulations described above.

Another linear regression model was created to predict the percent of axons activated in a fascicle, based on the distance of the fascicle from the electrode and the cube root of the voltage with $93 \%$ of the variability accounted for $\left(R^{2}=0.93\right)$. The radius of the fascicle was found to have a smaller impact on activation ( $p=0.08$ versus $p<2^{-16}$ for the other factors) and was not included in this model. When this fascicular model (see Eqn. 1) was used to predict whole nerve activation given the location of the 10 fascicles in cross section $C$ from Fig. 2, 98\% of the variability could be accounted for (Fig. 12). This suggests that a linear regression model could be used to generate data 
for different nerve cross-sectional arrangements which would decrease the model runtime for future configurations with the same electrode parameters.

FasciclePercentActivated $=-29.2-11.2 *($ Distance to Electrode $)+59.3 * \sqrt[3]{\text { Voltage }}$

\section{DISCUSSION}

An anatomically-based finite element model of the arm in combination with new motor and sensory axon models were used to predict axon activation in the median nerve. The axon models could reproduce experimental results for conduction velocity, strength-duration curves and activation threshold. Differences in action potential shape between the motor and sensory models reflected differences found in experimental recordings. The models predicted a lower threshold for sensory axons than motor axons of the same diameter, allowing a range of sensory axons to be activated before any motor axons.

\subsection{Arm Model}

Most prior research looking at nerve activation in the arm ignores the gross anatomy and simplifies the arm into a series of tissue layers (Goffredo et al. 2014; Keller and Kuhn 2008; Kuhn et al. 2009; Panescu et al. 1994; Sha et al. 2008). While still involving significant simplification, the two cross section model does account for much of the anatomical details that occur in the human arm directly under the electrodes. The size of muscles, amount of fat, diameter of the arm, and exact location of nerves varies across individuals but this model predicts activation voltages that are quite similar to those found experimentally (sensation threshold of 15-35V) (Forst et al. 2015).

\subsection{Axon Models}

Models that captured the differences between motor and sensory axons were needed to predict the differential activation of these fibers in the nerve. It has long been known that motor and sensory fibers respond differently to electrical stimulation. Early studies suggested that there were differences in their responses to pulse duration where sensory axons had a lower threshold at longer pulse durations and motor axons had a lower threshold at shorter pulse durations (Erlanger and Blair 1938; Veale et al. 1973). More recent findings did not confirm this difference but did confirm that sensory 
axons had a lower threshold than motor axons (Forst et al. 2015; Mogyoros et al. 1996; Panizza et al. 1994). The new models presented in this study were built using membrane properties derived from physiological data and/or validated in prior modeling studies. These new models also show that sensory axons have a lower activation threshold than motor axons for the same diameter.

The chronaxie times calculated from the strength-duration curves were found to be higher for sensory axons than for motor axons, consistent with experimental results (Bostock and Rothwell 1997; Mogyoros et al. 1996; Panizza et al. 1994). However, the chronaxie time for the sensory axon model reported here was slightly below the range reported experimentally ( $230 \mu \mathrm{s}$ vs. 300-700 $\mu \mathrm{s}$ ). This lower chronaxie time can also be seen in Fig. 7B in the differences in the curve of the model data compared to the experimental data, even though the model stayed within the experimental range. Because of this slight difference, threshold may be underestimated at lower pulse durations. Since our whole nerve experiments were performed at $100 \mu \mathrm{s}$, the predictions reported here should be minimally affected by this difference.

Differences were seen between the models and experimental data in the membrane voltage following the action potential. Even though the time durations of the model action potentials did not follow the experimental voltage, the changes in action potential shape that arose as motor parameters were converted to sensory values mirrored the differences between experimental recordings from motor and sensory axons. This suggests that the differences reported by Howells are appropriately converting the motor axon to a sensory axon. The inaccuracies during the afterpotential likely limit the use of these models to low frequency stimulation situations, where repeated stimuli only occur once the afterpotential would have concluded. Since the afterpotential has been reported to last up to $100 \mathrm{~ms}$ (C. Mclntyre et al. 2002), stimulation at or above $10 \mathrm{~Hz}$ should be acceptable.

\section{$\underline{4.3 \text { Sensitivity Analysis }}$}

Fast $\mathrm{Na}^{+}$conductance: The same value was used for fast $\mathrm{Na}^{+}$channel conductance in both the motor and sensory models as was suggested in the Howells model (Howells et al. 2012). Since the conductance was the same in both models and had a similar 
effect on threshold (from the sensitivity analysis), the actual choice of value was less important so the value from the MRG model was used. Any variability due to this choice should be similar between the two models.

HCN conductance: A value for HCN channel conductance could not be found in literature in the units of conductance per unit area, and the surface area of the internode used in the Howells model was not specified to allow the conversion of the value for use in the full axon model. A range of values were tested, and it was found that when the $\mathrm{HCN}$ conductance was too high, the axon fired spontaneously. Therefore, conductance values were investigated in the range that did not produce spontaneous firing in either the sensory or motor axon models. The ratio between the conductance of motor and sensory axons given in the Howells model (Howells et al. 2012) was maintained as values were altered for testing, because the focus was on the accuracy of the comparison between motor and sensory axons. Pairs of values fitting the ratio were tested in the motor and sensory models to find the pair that made the steady-state voltage in each model closest to the resting potential given for motor and sensory axons in Howells. These became the nominal values for $\mathrm{HCN}$ conductance: $2.232 \mathrm{mS} / \mathrm{cm}^{2}$ for motor and $3.102 \mathrm{mS} / \mathrm{cm}^{2}$ for sensory.

Leak conductances: The effect of altering leak conductance was slightly different based on the location of the channel. Doubling or halving the leak conductance in the MYSA had the greatest effect on threshold (15 $\pm 9 \%$ of threshold), but in the node or FLUT and STIN this also altered the threshold by about 1 volt ( $4.8 \pm 1 \%$ of threshold). The leak conductance in the node of the motor axon was retained from the MRG model. This was converted to an appropriate value for the sensory model using the ratio of sensory to motor nodal leak conductances reported in the Howells model. The internode leak was calculated based on the report that it had 35 times lower conductance than the node (Roper and Schwarz 1989). This process found leak conductance values in the internode of $0.2 \mathrm{mS} / \mathrm{cm}^{2}$ for motor and $0.1716 \mathrm{mS} / \mathrm{cm}^{2}$ for sensory. If the sensory value had been found by instead multiplying the motor internodal value by the Howells ratio of sensory to motor, the value would have been $0.1825 \mathrm{mS} / \mathrm{cm}^{2}$. This was a $6.3 \%$ increase in the parameter, and since this is much less than the $100 \%$ increase from the sensitivity analysis, the choice to maintain the exact ratio of node to internode, rather 
than the exact ratio of motor to sensory in the internode, should not have had a large effect on the final threshold. Since the nodal to internodal ratio was determined from experimental results, this method was preferable to specifying internodal conductance using model predictions. The use of these values for all internodal segments originally caused the axon models to fire spontaneously, so the leak conductance of the MYSA was increased in both the motor and sensory models to match the ratio between the conductance of MYSA and the conductance of FLUT and STIN in the MRG model. This eliminated the spontaneous firing and still maintained reported relationships between motor and sensory axons.

The leak conductance values affected the threshold by at most five volts when they were altered drastically by doubling or halving the chosen value in an axon with $12 \mu \mathrm{m}$ diameter. For an axon of this size, the difference in threshold between motor and sensory axons was about twelve volts. The basic model predictions can therefore be considered fairly resilient to variability in individual parameters. Additionally, since all of the sensory and motor conductance values were related by a fixed ratio from Howells et al., a change in one model would lead to a proportional change in the other. Since the sensitivity analysis shows that parameters have similar effects in both models, the comparison of motor and sensory thresholds is also resilient to parameter adjustments.

\subsection{Whole Nerve Activation}

At each voltage, larger axons were recruited at higher percentages than smaller axons, as expected. However, since axons of different diameters were distributed throughout the nerve, smaller axons were activated at voltages that did not fully activate the larger axons. For example some $13 \mu \mathrm{m}$ and $14 \mu \mathrm{m}$ fibers were activated at $15 \mathrm{~V}$, when $50 \%$ of the $15 \mu \mathrm{m}$ fibers were activated. This is similar to results reported using a simpler concentric tissue model of the arm (Goffredo et al. 2014).

Fascicular diameter was not found to be a significant contributor to axon activation $\left(p=0.08\right.$ and a change in $R^{2}$ of $0.07 \%$ ). Since the perineurium was set as a percentage of the fascicle diameter, prior studies have found that the activation threshold increases with larger fascicles. For example, change in percent activation of around $15 \%$ for a similar range of fascicle diameters as in the present study has been reported (Grinberg 
et al. 2008). It is likely that the greater distance from the electrodes and the significant amount of tissue for the current to travel through decreased the effect of the varying thickness of the perineurium.

\subsection{Additional Limitations and Implications}

Electrostatic simulations like the ones performed here have previously been successful at predicting activation using nerve-based electrodes (Schiefer et al. 2008). This solution method neglects the effect of tissue capacitance which will affect the shape and amplitude of the stimulation pulses within the tissue. Other models of surface stimulation using simplified geometry have used both electrostatic (Kuhn et al. 2010) and time-domain simulations which take into account capacitive effects of the different tissue types (Dorgan and Reilly 1999; Kuhn et al. 2009). The specific contribution of capacitive tissue properties in a detailed tissue model needs further investigation. Because the simulations neglect the effect of capacitance, other details of the model are less critical. For instance, the hydrogel layer of the electrode-skin interface was not included but a major effect of this layer is due to its capacitance. The overall effects of these FEM limitations on the electric field should be the same for all axons in the nerve. Therefore, the analysis and conclusions drawn about the relative activation of different axons based on their diameter, location or whether they were sensory or motor axons should be valid.

Consistent responses are difficult to obtain using surface electrical stimulation due to variable electrode placement, skin movement and physiological variables that effect tissue conductance. A viable clinical system must be able to overcome these challenges. The models presented here will be used to predict the function of an electrode array that would be placed over the elbow to achieve activation of multiple nerve locations across a range of anatomical variations. The model will also be used to design an algorithm that allows real-time adjustment of stimulation parameters based on user feedback to change the location of the evoked sensation. The model-optimized design will then be tested in human subjects to validate its effectiveness.

In addition, the sensory and motor axon models will play a vital role in the future development of sensory feedback systems for people with limb amputations. These 
models can be used to predict responses in other stimulating conditions, such as when using nerve cuff or intraneural electrodes. The ability to explore different stimulation methods to target motor or sensory axons will be invaluable. 


\section{REFERENCES}

Angeli, C. A., Edgerton, V. R., Gerasimenko, Y. P., \& Harkema, S. J. (2014). Altering spinal cord excitability enables voluntary movements after chronic complete paralysis in humans. Brain, 137(Pt 5), 1394-1409. doi:10.1093/brain/awu038awu038 [pii]

Birmingham, K., Gradinaru, V., Anikeeva, P., Grill, W. M., Pikov, V., McLaughlin, B., et al. (2014). Bioelectronic medicines: a research roadmap. Nat Rev Drug Discov, 13(6), 399-400. doi:10.1038/nrd4351nrd4351 [pii]

Bostock, H., Baker, M., \& Reid, G. (1991). Changes in excitability of human motor axons underlying postischaemic fasciculations: evidence for two stable states. $J$ Physiol, 441, 537-557. http://www.ncbi.nlm.nih.gov/pubmed/1667800

Bostock, H., \& Rothwell, J. C. (1997). Latent addition in motor and sensory fibres of human peripheral nerve. J Physiol, 498 ( Pt 1, 277-294. http://www.ncbi.nlm.nih.gov/pubmed/9023784

Boyd, I. A., \& Davey, M. R. (1968). Composition of peripheral nerves. Edinburgh, London,: E. \& S. Livingstone.

Boyd, I. A., \& Kalu, K. U. (1979). Scaling factor relating conduction velocity and diameter for myelinated afferent nerve fibres in the cat hind limb. $J$ Physiol, 289, 277-297. doi:10.1113/jphysiol.1979.sp012737

Buchthal, F., \& Rosenfalck, A. (1966). Number and diameter of myelinated fibres in human sensory nerves. Brain Research, 3(1), 85-94.

Choi, A. Q., Cavanaugh, J. K., \& Durand, D. M. (2001). Selectivity of multiple-contact nerve cuff electrodes: A simulation analysis. IEEE Transactions on Biomedical Engineering, 48(2), 165-172. doi:10.1109/10.909637

David, G., Modney, B., Scappaticci, K. A., Barrett, J. N., \& Barrett, E. F. (1995). Electrical and morphological factors influencing the depolarizing after-potential in rat and lizard myelinated axons. J Physiol, 489 ( Pt 1, 141-157. http://www.ncbi.nlm.nih.gov/pubmed/8583398

Dawson, G. D. (1956). The relative excitability and conduction velocity of sensory and motor nerve fibres in man. J Physiol, 131(2), 436-451. http://www.ncbi.nlm.nih.gov/pubmed/13320345

Dimbylow, P. J. (2000). Electromagnetic Field Calculations in an Anatomically Realistic Voxel Model of the Human Body. In B. J. Klauenberg \& D. Miklavcic (Eds.), Radio Frequency Radiation Dosimetry and its Relationship to the Biological Effects of Electromagnetic Fields (p. 127). Kluwer Academic Publishers.

Dorgan, S. J., \& Reilly, R. B. (1999). A model for human skin impedance during surface functional neuromuscular stimulation. IEEE Trans Rehabil Eng, 7(3), 341-348. http://www.ncbi.nlm.nih.gov/pubmed/10498379

Drillis, R., Contini, R., \& Bluestein, M. (1964). Body Segment Parameters; a Survey of Measurement Techniques. Artif Limbs, 8, 44-66. http://www.ncbi.nlm.nih.gov/pubmed/14208177

Elbow Cross Sectional Anatomy. (2014). Electronic Open Reduction Internal Fixation Reference. http://www.eorif.com/elbow-cross-sectional-anatomy

Erlanger, J., \& Blair, E. A. (1938). Comparative observations on motor and sensory fibers with special reference to repetitiousness. American Journal of Physiology, 121, 431-453.

Feinstein, B., Lindegard, B., Nyman, E., \& Wohlfart, G. (1955). Morphologic studies of motor units in normal human muscles. Acta Anat (Basel), 23(2), 127-142. http://www.ncbi.nlm.nih.gov/pubmed/14349537

Forst, J. C., Blok, D. C., Slopsema, J. P., Boss, J. M., Heyboer, L. A., Tobias, C. M., \& Polasek, K. H. (2015). Surface Electrical Stimulation to Evoke Referred Sensation. J Rehabil Res Dev, 52(4).

Geddes, L. A., \& Baker, L. E. (1967). The specific resistance of biological material--a compendium of data 
for the biomedical engineer and physiologist. Med Biol Eng, 5(3), 271-293.

http://www.ncbi.nlm.nih.gov/pubmed/6068939

Goffredo, M., Schmid, M., Conforto, S., Bilotti, F., Palma, C., Vegni, L., \& D'Alessio, T. (2014). A two-step model to optimise transcutaneous electrical stimulation of the human upper arm. Compel-the International Journal for Computation and Mathematics in Electrical and Electronic Engineering, 33(4), 1329-1345. doi:10.1108/Compel-04-2013-0118

Grill, W. M. (2004). Electrical Stimulation of the Peripheral Nervous System: Biophysics and Excitation Properties. In K. W. Horch \& K. Yoshida (Eds.), Neuroprosthetics: Theory and Practice (pp. 319340). World Scientific Publishing Co.

Grill, W., \& Mortimer, J. T. (1997). Inversion of the current-distance relationship by transient depolarization. IEEE Trans Biomed Eng, 44(1), 1-9.

http://www.ncbi.nlm.nih.gov/entrez/query.fcgi?cmd=Retrieve\&db=PubMed\&dopt=Citation\&list_uids= 9214779

Grinberg, Y., Schiefer, M. A., Tyler, D. J., \& Gustafson, K. J. (2008). Fascicular perineurium thickness, size, and position affect model predictions of neural excitation. IEEE Trans Neural Syst Rehabil Eng, 16(6), 572-581.

http://www.ncbi.nlm.nih.gov/entrez/query.fcgi?cmd=Retrieve\&db=PubMed\&dopt=Citation\&list_uids= 19144589

Hines, M. L., \& Carnevale, N. T. (1997). The NEURON simulation environment. Neural Comput, 9(6), 1179-1209. http://www.ncbi.nlm.nih.gov/pubmed/9248061

Howells, J., Trevillion, L., Bostock, H., \& Burke, D. (2012). The voltage dependence of I(h) in human myelinated axons. J Physiol, 590(Pt 7), 1625-1640.

doi:10.1113/jphysiol.2011.225573jphysiol.2011.225573 [pii]

Keller, T., \& Kuhn, A. (2008). Electrodes for transcutaneous (surface) electrical stimulation. Journal of Automatic Control, 18(2), 35-45. doi:10.2298/JAC0802035K

Kiernan, M. C., Mogyoros, I., \& Burke, D. (1996). Differences in the recovery of excitability in sensory and motor axons of human median nerve. Brain, 119 ( Pt 4, 1099-1105.

http://www.ncbi.nlm.nih.gov/pubmed/8813274

Kilgore, K. L., \& Bhadra, N. (2004). Nerve conduction block utilising high-frequency alternating current. Med Biol Eng Comput, 42(3), 394-406.

http://www.ncbi.nlm.nih.gov/entrez/query.fcgi?cmd=Retrieve\&db=PubMed\&dopt=Citation\&list_uids= 15191086

Kuhn, A., Keller, T., Lawrence, M., \& Morari, M. (2009). A model for transcutaneous current stimulation: simulations and experiments. Med Biol Eng Comput, 47(3), 279-289. doi:10.1007/s11517-0080422-z

Kuhn, A., Keller, T., Lawrence, M., \& Morari, M. (2010). The influence of electrode size on selectivity and comfort in transcutaneous electrical stimulation of the forearm. IEEE Trans Neural Syst Rehabil Eng, 18(3), 255-262. doi:10.1109/TNSRE.2009.2039807

Mclntyre, C. C., \& Grill, W. M. (2002). Extracellular Stimulation of Central Neurons : Influence of Stimulus Waveform and Frequency on Neuronal Output. J Neurop, 88, 1592-1604.

McIntyre, C., Richardson, A. G., \& Grill, W. M. (2002). Modeling the excitability of mammalian nerve fibers: influence of afterpotentials on the recovery cycle. J Neurophysiol, 87gr(2), 995-1006.

http://www.ncbi.nlm.nih.gov/entrez/query.fcgi?cmd=Retrieve\&db=PubMed\&dopt=Citation\&list_uids= 11826063

Medina, L. E., \& Grill, W. M. (2016). Nerve excitation using an amplitude-modulated signal with kilohertzfrequency carrier and non-zero offset. Journal of NeuroEngineering and Rehabilitation, 13(1), 63. doi:10.1186/s12984-016-0171-4

Miles, J. D., Kilgore, K. L., Bhadra, N., \& Lahowetz, E. A. (2007). Effects of ramped amplitude waveforms 
on the onset response of high-frequency mammalian nerve block. J Neural Eng, 4(4), 390-398. http://www.ncbi.nlm.nih.gov/entrez/query.fcgi?cmd=Retrieve\&db=PubMed\&dopt=Citation\&list_uids= 18057506

Mogyoros, I., Kiernan, M. C., \& Burke, D. (1996). Strength-duration properties of human peripheral nerve. Brain, 119 ( Pt 2, 439-447.

http://www.ncbi.nlm.nih.gov/entrez/query.fcgi?cmd=Retrieve\&db=PubMed\&dopt=Citation\&list_uids= 8800939

Panescu, D., Webster, J. G., \& Stratbucker, R. A. (1994). A Nonlinear Finite Element Model of the Electrode-Electrolyte-Skin System. IEEE Trans Biomed Eng, 41(7), 681-687.

Panizza, M., Nilsson, J., Roth, B. J., Rothwell, J., \& Hallett, M. (1994). The time constants of motor and sensory peripheral nerve fibers measured with the method of latent addition. Electroencephalogr Clin Neurophysiol, 93(2), 147-154. http://www.ncbi.nlm.nih.gov/pubmed/7512921

Peterson, E. J., Izad, O., \& Tyler, D. J. (2011). Predicting myelinated axon activation using spatial characteristics of the extracellular field. J Neural Eng, 8(4), 46030. doi:10.1088/17412560/8/4/046030S1741-2560(11)82338-4 [pii]

Peurala, S. H., Pitkanen, K., Sivenius, J., \& Tarkka, I. M. (2002). Cutaneous electrical stimulation may enhance sensorimotor recovery in chronic stroke. Clin Rehabil, 16(7), 709-716. http://www.ncbi.nlm.nih.gov/pubmed/12428819

Ranck, J. B., \& BeMent, S. L. (1965). The specific impedance of the dorsal columns of cat: an anisotropic medium. Experimental Neurology, 11(4), 451-463. doi:10.1016/0014-4886(65)90059-2

Roper, J., \& Schwarz, J. R. (1989). Heterogeneous distribution of fast and slow potassium channels in myelinated rat nerve fibres. J Physiol, 416, 93-110. https://www.ncbi.nlm.nih.gov/pmc/articles/PMC1189205/

Schiefer, M. A., Triolo, R. J., \& Tyler, D. J. (2008). A model of selective activation of the femoral nerve with a flat interface nerve electrode for a lower extremity neuroprosthesis. IEEE Trans Neural Syst Rehabil Eng, 16(2), 195-204.

http://www.ncbi.nlm.nih.gov/entrez/query.fcgi?cmd=Retrieve\&db=PubMed\&dopt=Citation\&list_uids= 18403289

Sha, N., Kenney, L. P. J., Heller, B. W., Barker, A. T., Howard, D., \& Moatamedi, M. (2008). A Finite Element Model to Identify Electrode Influence on Current Distribution in the Skin, 32(8), 639-643. doi:10.1111/j.1525-1594.2008.00615.x

Stebbing, M. J., Eschenfelder, S., Habler, H. J., Acosta, M. C., Janig, W., \& McLachlan, E. M. (1999). Changes in the action potential in sensory neurones after peripheral axotomy in vivo. Neuroreport, 10(2), 201-206. doi:10.1097/00001756-199902050-00001

Sunderland, S. (1978). Nerves and Nerve Injury (2nd ed.). New York: Churchill Livingstone.

Suresh, S., Smith, L., \& Tyler, D. J. (2006). Fascicular Anatomy of Upper Extremity Nerves for Neuroprosthesis Development. In Biomedical Engineering Society. Chicago, IL.

Veale, J. L., Mark, R. F., \& Rees, S. (1973). Differential sensitivity of motor and sensory fibres in human ulnar nerve. J Neurol Neurosurg Psychiatry, 36(1), 75-86. http://www.ncbi.nlm.nih.gov/pubmed/4348037

Walker, E. R., Hyngstrom, A. S., \& Schmit, B. D. (2014). Sensory electrical stimulation improves foot placement during targeted stepping post-stroke. Exp Brain Res. doi:10.1007/s00221-014-3823-2

Warman, E. N., Grill, W. M., \& Durand, D. (1992). Modeling the effects of electric fields on nerve fibers: determination of excitation thresholds. IEEE Trans Biomed Eng, 39(12), 1244-1254. http://www.ncbi.nlm.nih.gov/pubmed/1487287

Weerasuriya, A., Spangler, R. A., Rapoport, S. I., \& Taylor, R. E. (1984). AC impedance of the perineurium of the frog sciatic nerve. Biophysical Journal, 46(2), 167-174. doi:10.1016/S00063495(84)84009-6 
Wesselink, W. A., Holsheimer, J., \& Boom, H. B. (1999). A model of the electrical behaviour of myelinated sensory nerve fibres based on human data. Med Biol Eng Comput, 37(2), 228-235. http://www.ncbi.nlm.nih.gov/pubmed/10396827

Wongsarnpigoon, A., Woock, J. P., \& Grill, W. M. (2010). Efficiency analysis of waveform shape for electrical excitation of nerve fibers. IEEE Trans Neural Syst Rehabil Eng, 18(3), 319-328. doi:10.1109/TNSRE.2010.2047610 


\section{FIGURES}

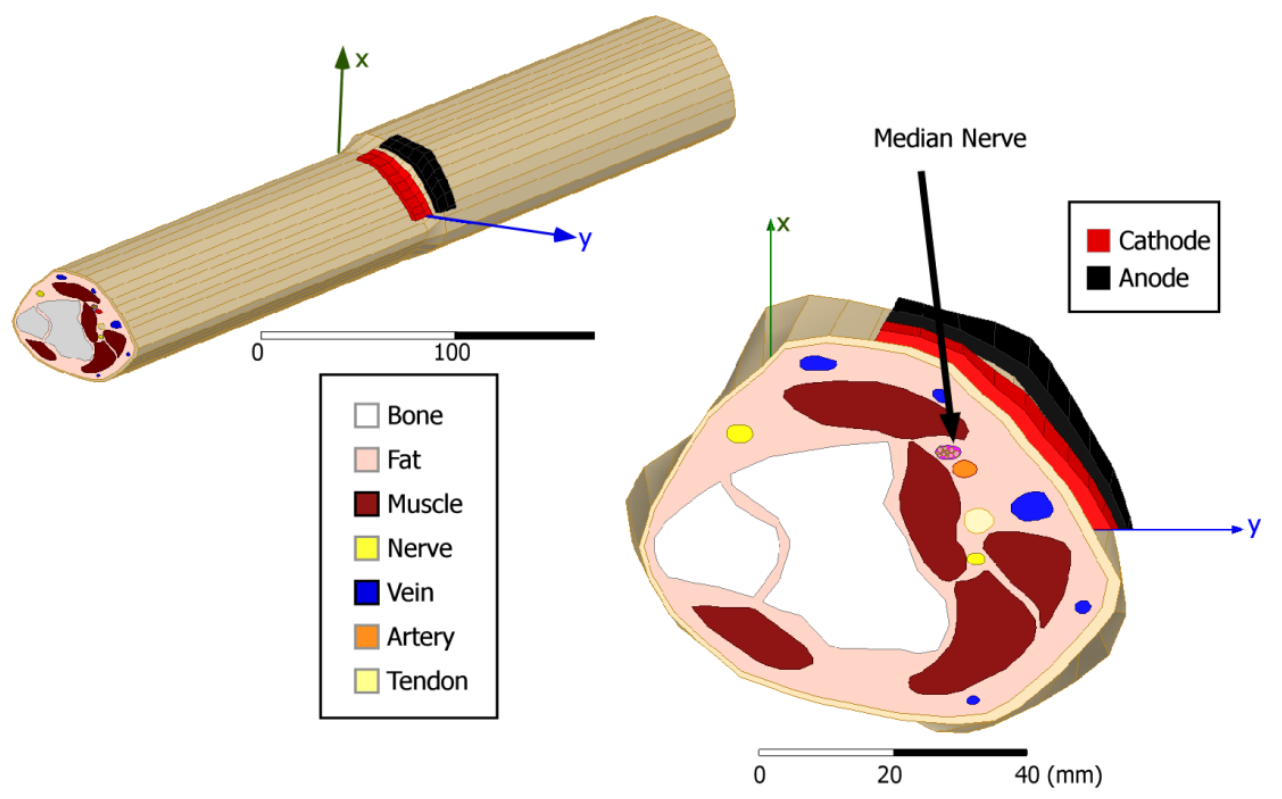

Fig. 1 The Modeled Arm, in ANSYS Maxwell. The electrodes are placed over the elbow 

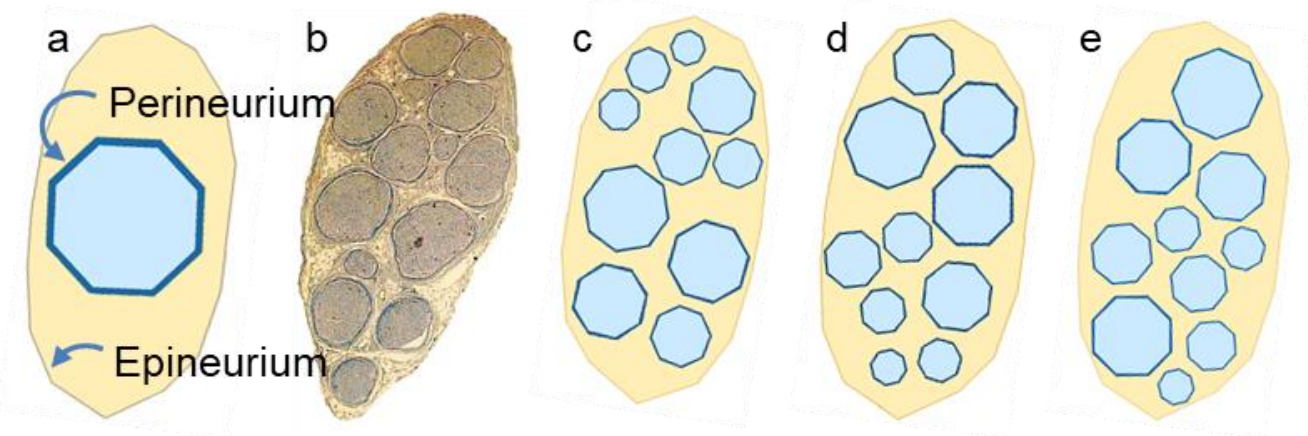

Fig. 2 Nerve cross-sections. (a) Single fascicle nerve used for initial testing of axon models. (b) Median nerve cross section from the elbow of a human cadaver. (c-e) Modeled versions of the median nerve with randomly arranged fascicles 


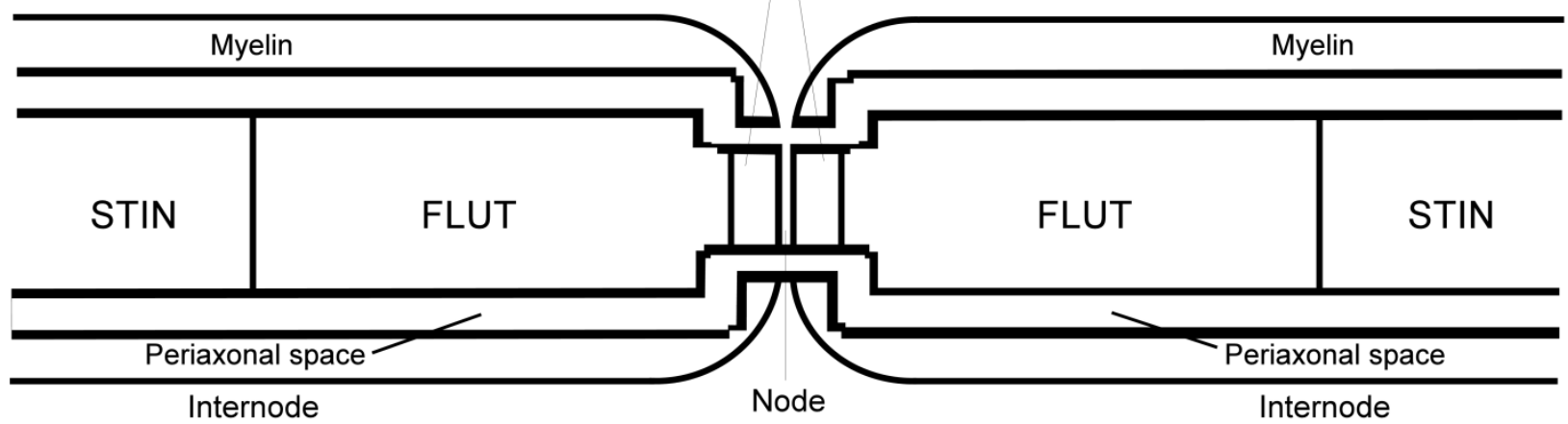

b

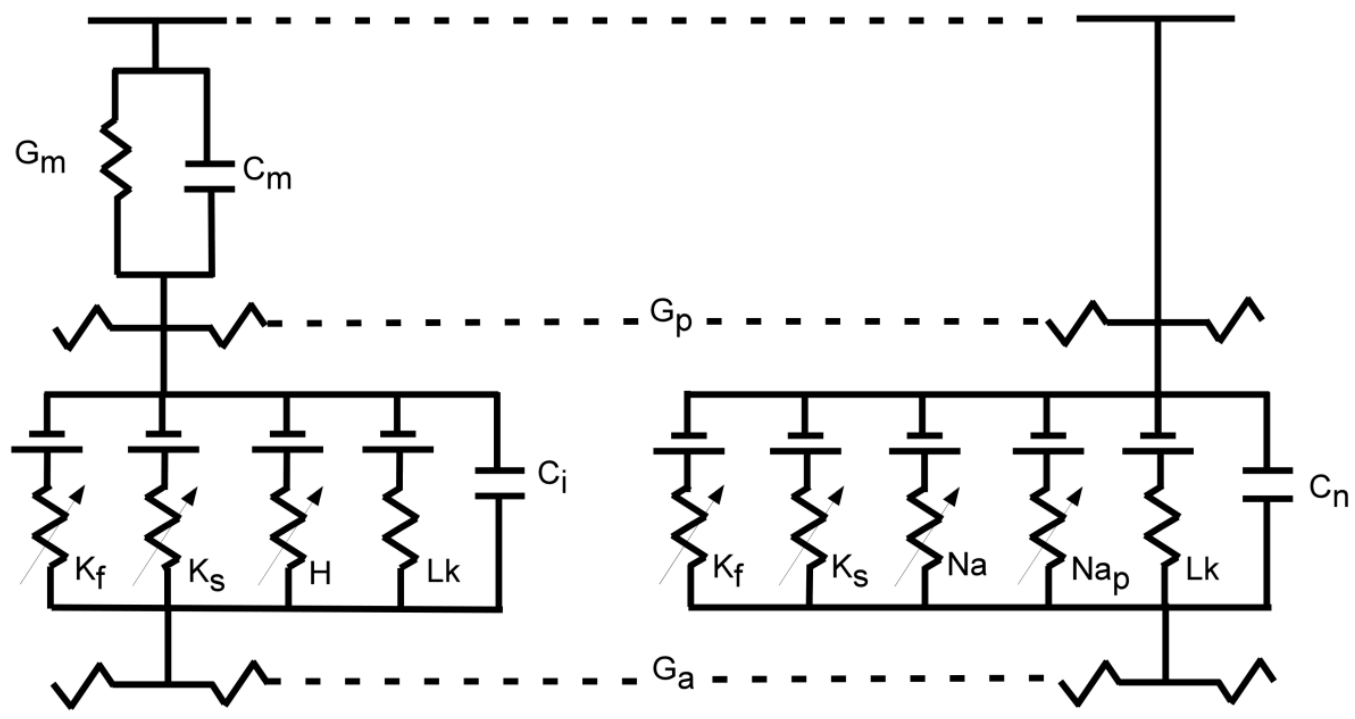

Internodal channels

Nodal channels

Fig. 3 Overview of the Models. (a) Overall structure of the axon model. Between each node of Ranvier are two MYSA segments, two FLUT segments, and six STIN segments. Together, these segments make up the internode, which is sheathed in myelin. The model contains 161 nodes and 160 internodes. (b) The ion channels modeled as voltagedependent resistors. The internodal segments contain fast $\mathrm{K}^{+}$, slow $\mathrm{K}^{+}$, and $\mathrm{HCN}$ channels, with leak resistance and internodal capacitance. The node contains fast $\mathrm{K}^{+}$, slow $\mathrm{K}^{+}$, fast $\mathrm{Na}^{+}$, persistent $\mathrm{Na}^{+}$, and leak channels, with nodal capacitance. Also represented are the conductance $G_{m}$ and capacitance $C_{m}$ of the myelin, the axoplasmic conductance $G_{a}$, and the periaxonal conductance $G_{p}$ 


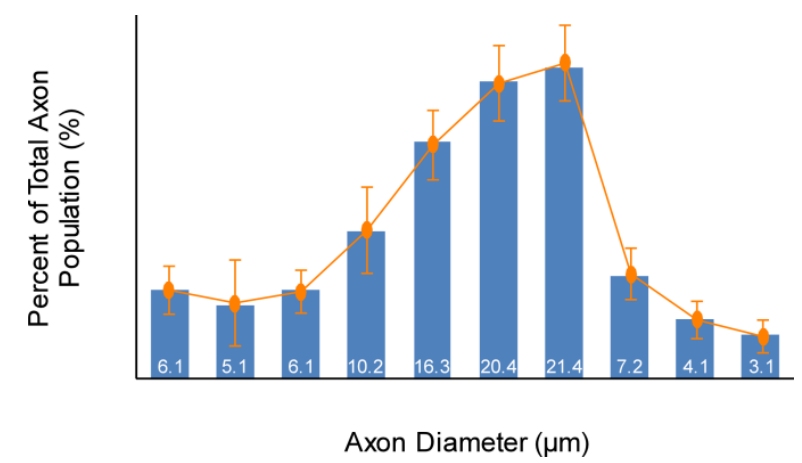

Fig. 4 Distribution of Axon Diameters in the Median Nerve. Blue bars are the distribution reported by Buchthal with the height of the bar listed at the base (Buchthal and Rosenfalck 1966). The orange points show the actual distribution that resulted from the random assignment of axon diameters (error bars denote one standard deviation). Note that axons with diameters less than $6 \mu \mathrm{m}$ were not included because they were not activated by voltages within the experimental range of 1-50 V 


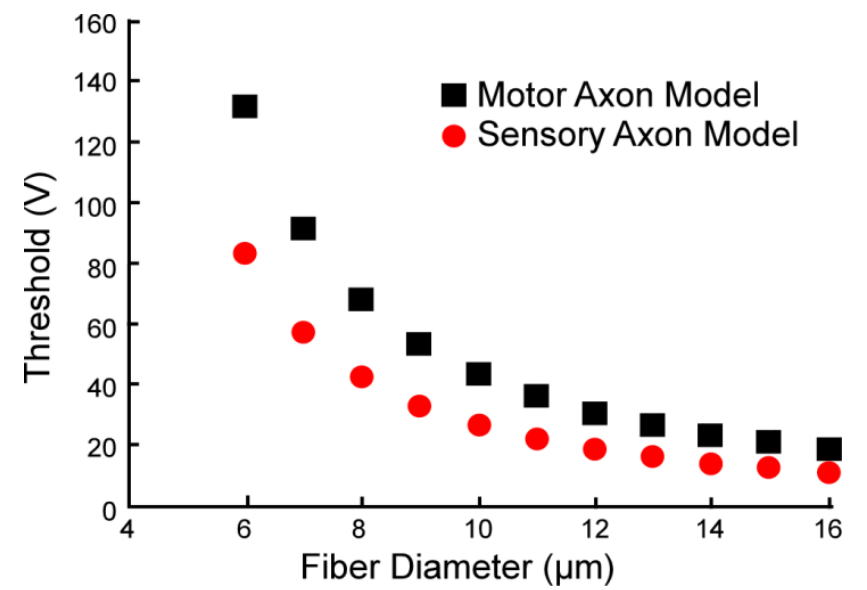

Fig. 5 Comparison of motor and sensory thresholds for different fiber diameters 


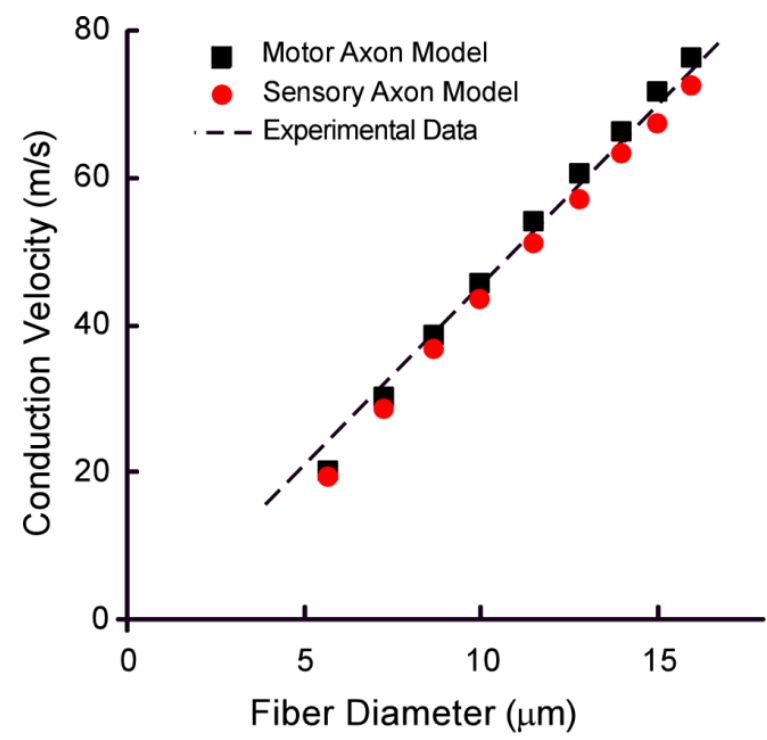

Fig. 6 The relationship between conduction velocity and fiber diameter in the model closely resembled the relationship measured in cats. The dotted line was obtained from the equation fit to the group I afferent fibers and adjusted for the assumed $20 \%$ shrinkage reported in the study (I A Boyd and Kalu 1979) 

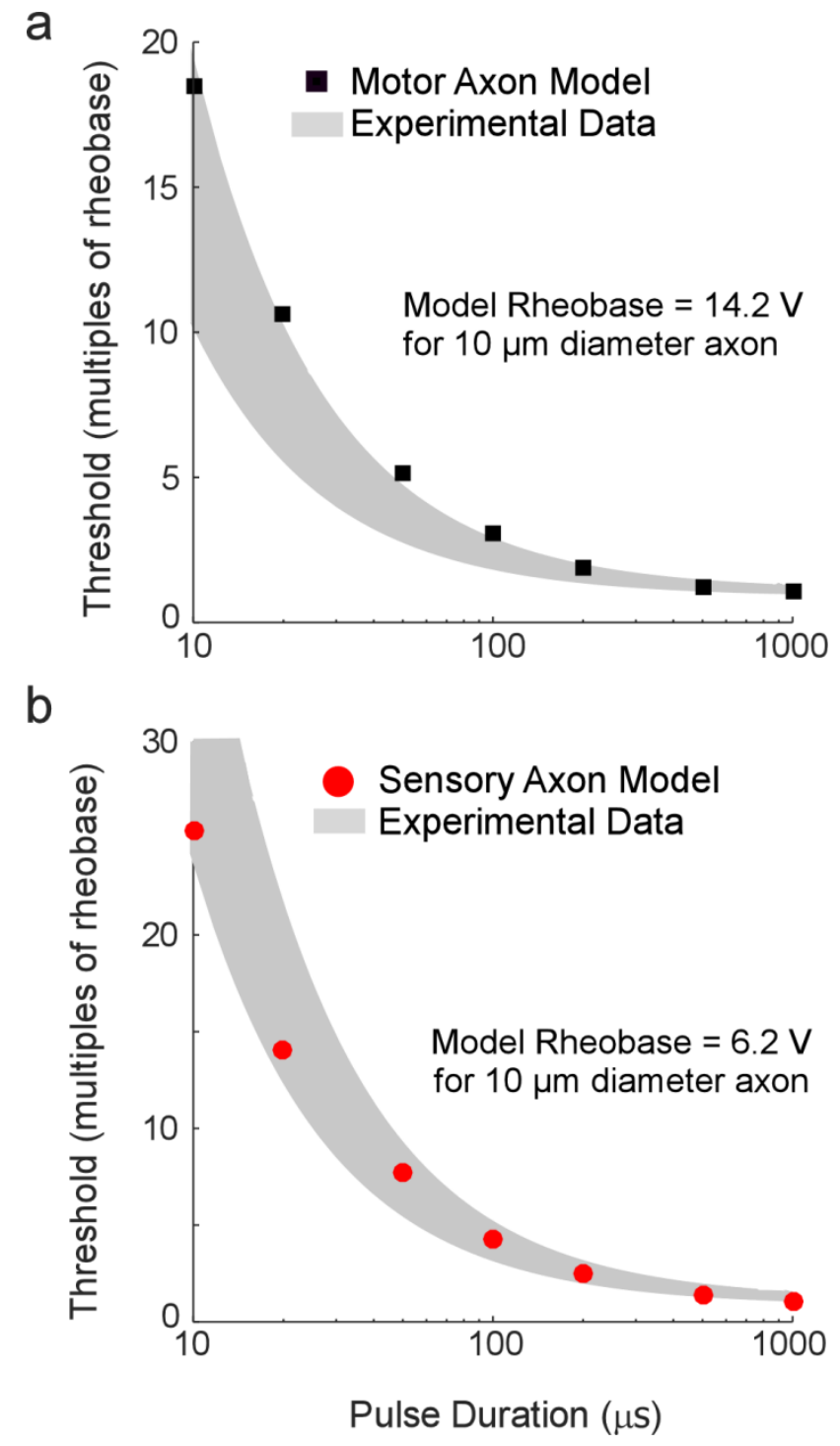

Fig. 7 Normalized strength-duration curves from a single motor (a) and sensory (b) axon in the singular fasicular median nerve. The grey areas were drawn using the mean and standard deviation reported experimentally (Panizza et al. 1994) 
a

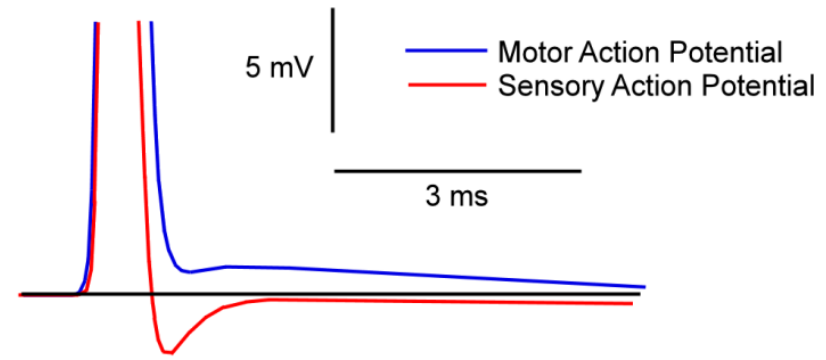

b

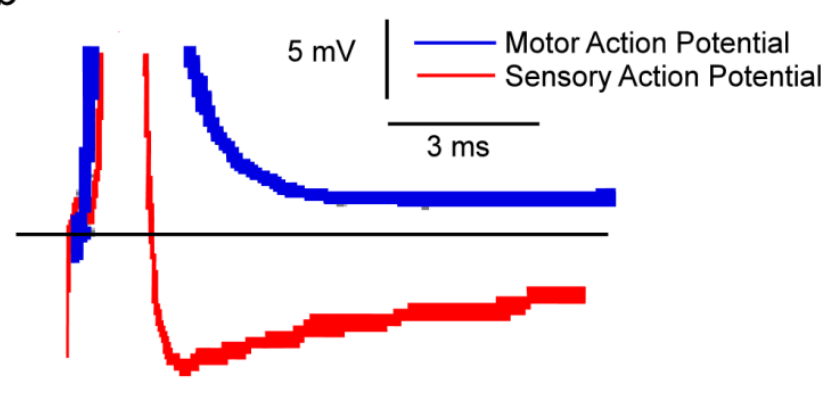

Fig. 8 Shape of the action potential. (a) Model action potentials. (b) Experimental action potentials. The differences observed between the motor and sensory action potential shapes in the model (a) are also reflected in action potentials observed experimentally (b) in motor (David et al. 1995) and sensory (Stebbing et al. 1999) axons 


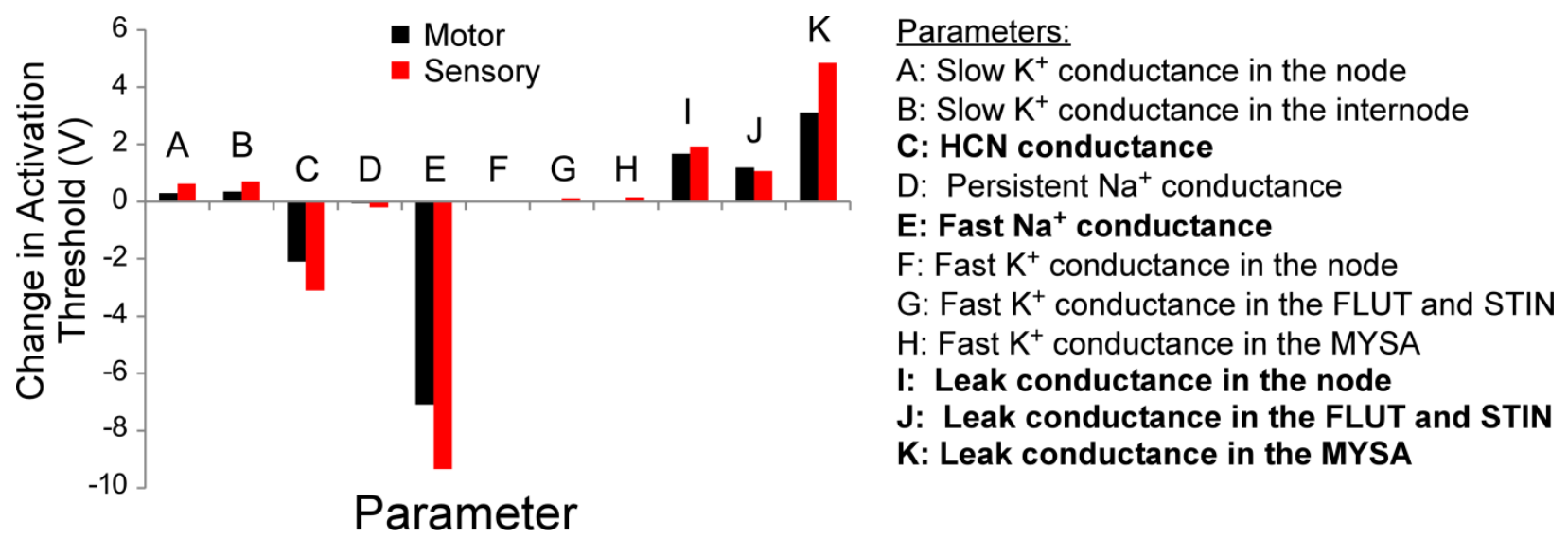

Fig. 9 Sensitivity analysis of the effect of doubling each parameter from its nominal threshold value in motor and sensory axon models. Halving each parameter yielded similar results so these data are not included. The most influential parameters were the fast sodium channel conductance, HCN channel conductance, and leak conductance 
a

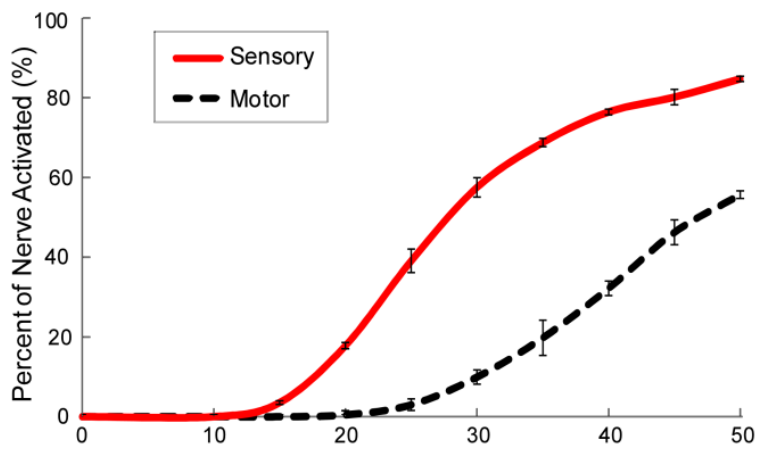

b

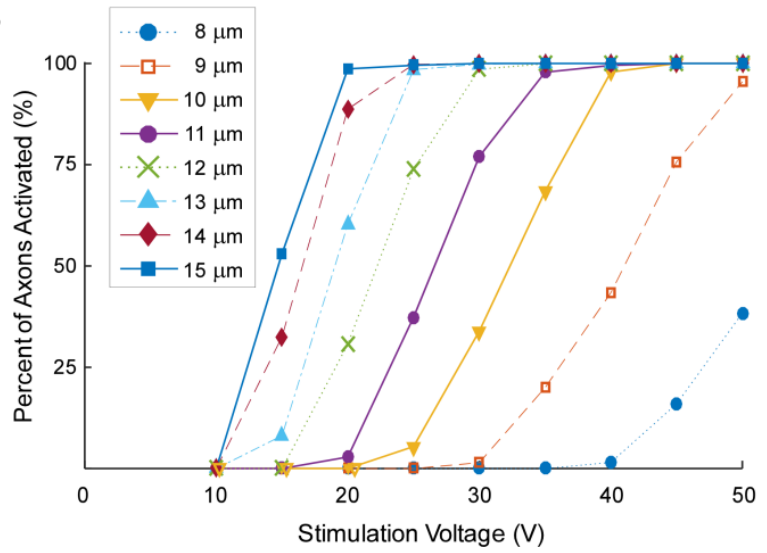

Fig. 10 Activation across the three median nerve cross sections calculated using a weighted sum of the activation from each fascicle. (a) Sensory and motor axon percent activation at each voltage. Sensory axons were activated at a higher percentage than motor axons for all voltages. Error bars are one standard deviation. (b) Activation percentage by diameter of axon, regardless of location within the nerve and including motor and sensory fibers. A higher percentage of larger diameter axons were activated at lower voltages. Voltages up to $50 \mathrm{~V}$ were tested to be consistent with experimental protocol 


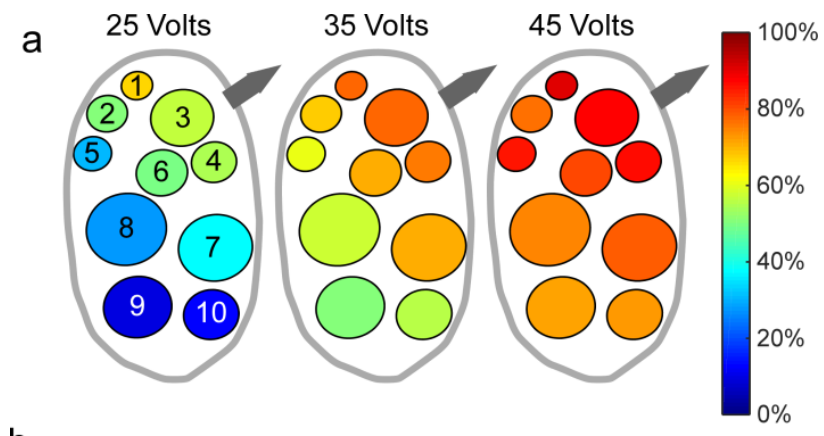

b

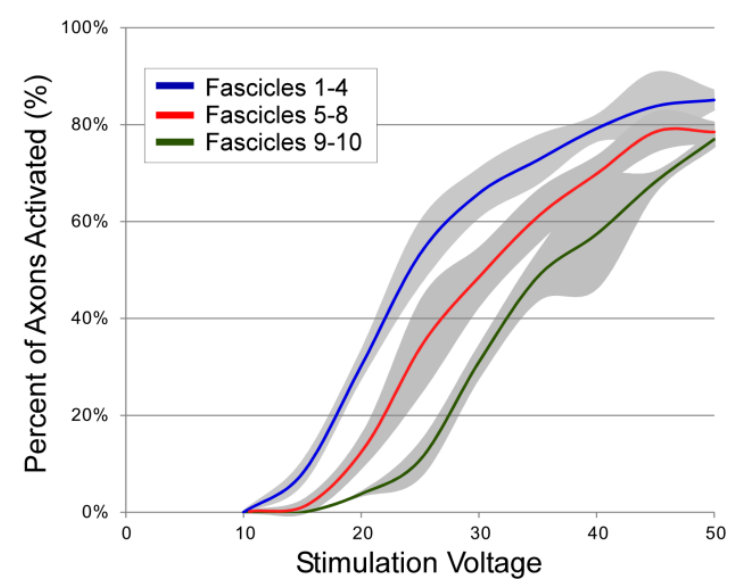

Fig. 11 (a) Comparison of percent activation of fascicles using crosssection $\mathrm{C}$, including both axon types and all axon diameters. Fascicles closest to the electrodes were activated at higher percentages than further fascicles (grey arrows indicate approximate electrode location. There were three discrete groups of fascicles with similar activation patterns, shown in (b). The grey shading corresponds to one standard deviation. The fascicle numbers in the legend in (b) correspond to the labels from (a) 


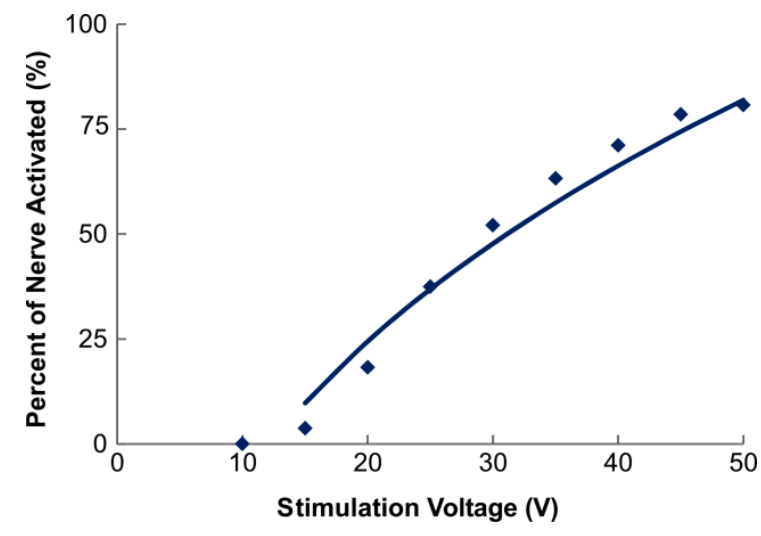

Fig. 12 Linear regression prediction (line) compared to data from crosssection C (Fig. 2) of the median nerve (diamonds) 


\section{Appendix A}

Ion channel currents:

$$
\begin{array}{ll}
I_{N a}=g_{N a} * m^{3} * h *\left(v-E_{N a}\right) & \text { (Fast sodium) } \\
I_{N a p}=g_{N a p} * p^{3} *\left(v-E_{N a}\right) & \text { (Persistent sodium) } \\
I_{K s}=g_{K s} * s *\left(v-E_{K}\right) & \text { (Slow potassium) } \\
I_{K f}=g_{K f} * n^{4} *\left(v-E_{K f}\right) & \text { (Fast potassium) } \\
I_{q}=g_{q} * q *\left(v-E_{q}\right) & \text { (HCN) } \\
I_{L k}=g_{L k} *\left(v-E_{L k}\right) & \text { (Leak) }
\end{array}
$$

where $g$ is the conductance and $E$ is the reversal potential.

For a given gating parameter $\mathrm{x}$ :

$$
\begin{gathered}
\frac{\mathrm{d} x}{\mathrm{~d} t}=\alpha_{x}(1-x)-\beta_{x} x \\
\tau=\frac{1}{\alpha+\beta}
\end{gathered}
$$

Where $\alpha$ and $\beta$ are defined as:

$$
\begin{gathered}
\alpha_{m}, \alpha_{p}=Q_{10} * \frac{A *(v+B)}{1-e^{\left[-\frac{v+B}{C}\right]}} \\
\beta_{m}, \beta_{p}, \alpha_{h}=Q_{10} * \frac{A *[-(v+B)]}{1-e^{\left[\frac{v+B}{C}\right]}} \\
\beta_{h}=Q_{10} * \frac{A}{1+e^{\left[-\frac{v+B}{C}\right]}} \\
\alpha_{s}, \beta_{s}=Q_{10} * \frac{A}{e^{\left[\frac{v+B}{C}\right]}+1} \\
\alpha_{n}=Q_{10} * \frac{A *(v-B)}{1-e^{\left[\frac{B-v}{C}\right]}} \\
\beta_{n}=Q_{10} * \frac{A *(B-v)}{1-e^{\left[\frac{v-B}{C}\right]}} \\
\alpha_{q}=Q_{10} * A * e^{\left[\frac{v-B}{C}\right]} \\
\beta_{q}=Q_{10} * \frac{A}{e^{\left[\frac{v-B}{C}\right]}}
\end{gathered}
$$

and $Q_{10}$ is the temperature coefficient. 


\section{Appendix B}

Motor Axon Parameters:

\begin{tabular}{|c|c|c|c|c|c|c|}
\hline & \multicolumn{3}{|c|}{ Node } & \multicolumn{3}{|c|}{ Internode } \\
\hline $\begin{array}{l}\text { Voltage and } \\
\text { time dependent } \\
\text { parameters }\end{array}$ & $A(m s-1)$ & $\mathrm{B}(\mathrm{mV})$ & $C(m V)$ & $A(m s-1)$ & $B(m V)$ & $\mathrm{C}(\mathrm{mV})$ \\
\hline$\alpha_{m}$ & $1.86^{i}$ & $20.4^{i}$ & $10.3^{i}$ & -- & -- & -- \\
\hline$\beta_{m}$ & $0.086^{i}$ & $25.7^{i}$ & $9.16^{i}$ & -- & -- & -- \\
\hline$\alpha_{m p}$ & $0.01^{i}$ & $27^{i}$ & $10.2^{\mathrm{i}}$ & -- & -- & -- \\
\hline$\beta_{m p}$ & $0.00025^{i}$ & $34^{i}$ & $10^{i}$ & -- & -- & -- \\
\hline$\alpha_{h}$ & $0.062^{i}$ & $114.0^{i}$ & $11.0^{\mathrm{i}}$ & -- & -- & -- \\
\hline$\beta_{h}$ & $2.3^{\mathrm{i}}$ & $31.8^{i}$ & $13.4^{\mathrm{i}}$ & -- & -- & -- \\
\hline$\alpha_{n}$ & $0.0462^{i}$ & $-83.2^{i}$ & $1.1^{\mathrm{i}}$ & $0.0462^{i}$ & $-83.2^{i}$ & $1.1^{i}$ \\
\hline$\beta_{n}$ & $0.0824^{i}$ & $-66^{i}$ & $10.5^{\mathrm{i}}$ & $0.0824^{i}$ & $-66^{i}$ & $10.5^{i}$ \\
\hline$\alpha_{s}$ & $0.3^{i}$ & $-27^{i}$ & $-5^{i}$ & $0.3^{i}$ & $-27^{i}$ & $-5^{i}$ \\
\hline$\beta_{s}$ & $0.03^{i}$ & $10^{i}$ & $-1^{\mathrm{i}}$ & $0.03^{i}$ & $10^{i}$ & $-1^{i}$ \\
\hline$\alpha_{q}$ & -- & -- & -- & $0.00522^{\mathrm{ii}}$ & $-107.3^{i i}$ & $-12.2^{\mathrm{iv}}$ \\
\hline$\beta_{q}$ & -- & -- & -- & $0.00522^{\mathrm{ii}}$ & $-107.3^{i i}$ & $-12.2^{\mathrm{iv}}$ \\
\hline $\begin{array}{l}\text { Channel } \\
\text { Conductances }\end{array}$ & \multicolumn{3}{|c|}{$\left(\mathrm{mS} \mathrm{cm} \mathrm{cm}^{-2}\right)$} & \multicolumn{3}{|c|}{$\left(\mathrm{mS} \mathrm{cm} \mathrm{cm}^{-2}\right)$} \\
\hline $\begin{array}{l}\text { Persistent } \\
\text { Sodium }\end{array}$ & \multicolumn{3}{|c|}{$10^{\mathrm{i}}$} & \multicolumn{3}{|c|}{--} \\
\hline $\begin{array}{l}\text { Fast } \\
\text { Sodium }\end{array}$ & \multicolumn{3}{|c|}{$3000^{i}$} & \multicolumn{3}{|c|}{--} \\
\hline $\begin{array}{l}\text { Slow } \\
\text { Potassium }\end{array}$ & \multicolumn{3}{|c|}{$80^{\mathrm{i}}$} & \multicolumn{3}{|c|}{$2.581^{\mathrm{iv}}$} \\
\hline $\begin{array}{l}\text { Fast } \\
\text { Potassium }\end{array}$ & \multicolumn{3}{|c|}{$25.68^{i i i}$} & \multicolumn{3}{|c|}{$150.74(\text { MYSA) })^{\mathrm{iv}}, 25.68$ (FLUT, STIN) $)^{\mathrm{iv}}$} \\
\hline Leak & \multicolumn{3}{|c|}{$7^{i}$} & \multicolumn{3}{|c|}{$2(\mathrm{MYSA})^{\mathrm{v}}, 0.2$ (FLUT, STIN) ${ }^{\mathrm{iv}}$} \\
\hline $\mathrm{HCN}$ & \multicolumn{3}{|c|}{--} & \multicolumn{3}{|c|}{$2.232^{\mathrm{iii}}$} \\
\hline $\begin{array}{l}\text { Reversal } \\
\text { Potentials }\end{array}$ & \multicolumn{3}{|c|}{$(\mathrm{mV})$} & \multicolumn{3}{|c|}{$(\mathrm{mV})$} \\
\hline Sodium & \multicolumn{3}{|c|}{$50.0^{\mathrm{i}}$} & \multicolumn{3}{|c|}{--} \\
\hline $\begin{array}{l}\text { Slow } \\
\text { Potassium }\end{array}$ & \multicolumn{3}{|c|}{$-90.0^{\mathrm{i}}$} & \multicolumn{3}{|c|}{$-90.0^{\mathrm{i}}$} \\
\hline $\begin{array}{l}\text { Fast } \\
\text { Potassium }\end{array}$ & \multicolumn{3}{|c|}{-90.0} & \multicolumn{3}{|c|}{-90.0} \\
\hline Leak & \multicolumn{3}{|c|}{$-90.0^{i}$} & \multicolumn{3}{|c|}{$-90.0^{i}$} \\
\hline $\mathrm{HCN}$ & \multicolumn{3}{|c|}{-- } & \multicolumn{3}{|c|}{$-54.9^{v i}$} \\
\hline
\end{tabular}




\section{Sensory Axon Parameters}

\begin{tabular}{|c|c|c|c|c|c|c|}
\hline & \multicolumn{3}{|c|}{ Node } & \multicolumn{3}{|c|}{ Internode } \\
\hline $\begin{array}{l}\text { Voltage and time } \\
\text { dependent } \\
\text { parameters }\end{array}$ & $A\left(m s^{-1}\right)$ & $B(m V)$ & $\mathrm{C}(\mathrm{mV})$ & $A\left(m^{-1}\right)$ & $B(m V)$ & $C(m V)$ \\
\hline$\alpha m$ & $1.77753^{\mathrm{vii}}$ & $20.1795^{\text {vii }}$ & $10.3^{\text {viii }}$ & -- & -- & -- \\
\hline$\beta m$ & $0.0823^{\text {vii }}$ & $25.4746^{\mathrm{vii}}$ & $9.16^{\text {viii }}$ & -- & -- & -- \\
\hline$a m p$ & $0.00957^{\mathrm{vii}}$ & $26.852^{\mathrm{vii}}$ & $10.2^{\mathrm{viii}}$ & -- & -- & -- \\
\hline$\beta m p$ & $0.00024^{\mathrm{vii}}$ & $33.8333^{\mathrm{vii}}$ & $10^{\text {viii }}$ & -- & -- & -- \\
\hline ah & $0.075286^{v i i}$ & $112.7124^{v i i}$ & $8.391^{\mathrm{vii}}$ & -- & -- & -- \\
\hline$\beta h$ & $2.8083^{v i i}$ & $30.5435^{\mathrm{vii}}$ & $10.2263^{\text {vii }}$ & -- & -- & -- \\
\hline an & $0.0462^{\text {viii }}$ & $-83.2^{\text {viii }}$ & $1.1^{\text {viii }}$ & $0.0462^{\text {viii }}$ & $-83.2^{\text {viii }}$ & $1.1^{\text {viii }}$ \\
\hline$\beta n$ & $0.0824^{\text {viii }}$ & $-66^{\text {viii }}$ & $10.5^{\text {viii }}$ & $0.0824^{\text {viii }}$ & $-66^{\text {viii }}$ & $10.5^{\text {viii }}$ \\
\hline as & $0.3^{\text {viii }}$ & $-27^{v i i i}$ & $-5^{\mathrm{viii}}$ & $0.3^{\text {viii }}$ & $-27^{\text {viii }}$ & $-5^{\text {viii }}$ \\
\hline$\beta s$ & $0.03^{\text {viii }}$ & $10^{\text {viii }}$ & $-1^{\text {viii }}$ & $0.03^{\text {viii }}$ & $10^{\text {viii }}$ & $-1^{\text {viii }}$ \\
\hline$\alpha q$ & -- & -- & -- & $0.00522^{\mathrm{ii}}$ & $-94.2^{\mathrm{ii}}$ & $-12.2^{i i}$ \\
\hline$\beta q$ & -- & -- & -- & $0.00522^{i i}$ & $-94.2^{\mathrm{ii}}$ & $-12.2^{i i}$ \\
\hline $\begin{array}{l}\text { Channel } \\
\text { Conductances }\end{array}$ & \multicolumn{3}{|c|}{$\left(\mathrm{mS} \mathrm{cm} \mathrm{cm}^{-2}\right)$} & \multicolumn{3}{|c|}{$\left(\mathrm{mS} \mathrm{cm} \mathrm{cm}^{-2}\right)$} \\
\hline $\begin{array}{l}\text { Persistent } \\
\text { Sodium }\end{array}$ & \multicolumn{3}{|c|}{$10^{\text {viii }}$} & \multicolumn{3}{|c|}{--} \\
\hline Fast Sodium & \multicolumn{3}{|c|}{$3000^{\text {viii }}$} & \multicolumn{3}{|c|}{--} \\
\hline $\begin{array}{l}\text { Slow } \\
\text { Potassium }\end{array}$ & \multicolumn{3}{|c|}{$41.06^{\mathrm{vii}}$} & \multicolumn{3}{|c|}{$1.324^{\mathrm{iv}}$} \\
\hline $\begin{array}{l}\text { Fast } \\
\text { Potassium }\end{array}$ & \multicolumn{3}{|c|}{$27.37^{\mathrm{iii}}$} & \multicolumn{3}{|c|}{164.2 (MYSA)iv, 27.37 (FLUT,STIN)iv } \\
\hline Leak & \multicolumn{3}{|c|}{$6.005^{\mathrm{vii}}$} & \multicolumn{3}{|c|}{1.716 (MYSA) $^{\mathrm{v}}, 0.1716$ (FLUT,STIN)iv } \\
\hline $\mathrm{HCN}$ & \multicolumn{3}{|c|}{--} & \multicolumn{3}{|c|}{$3.102^{\mathrm{iii}}$} \\
\hline $\begin{array}{l}\text { Reversal } \\
\text { Potentials }\end{array}$ & \multicolumn{3}{|c|}{$(\mathrm{mV})$} & \multicolumn{3}{|c|}{$(\mathrm{mV})$} \\
\hline Sodium & \multirow{2}{*}{\multicolumn{3}{|c|}{$\begin{array}{l}50.0^{\text {viii }} \\
-90.0^{\text {viii }}\end{array}$}} & \multicolumn{3}{|c|}{--} \\
\hline $\begin{array}{l}\text { Slow } \\
\text { Potassium }\end{array}$ & & & & & $-90.0^{\text {viii }}$ & \\
\hline $\begin{array}{l}\text { Fast } \\
\text { Potassium }\end{array}$ & \multicolumn{3}{|c|}{$-90.0^{\text {viii }}$} & \multicolumn{3}{|c|}{$-90.0^{v i i i}$} \\
\hline Leak & \multicolumn{3}{|c|}{$-90.0^{\text {viii }}$} & \multicolumn{3}{|c|}{$-90.0^{\text {viii }}$} \\
\hline $\mathrm{HCN}$ & \multicolumn{3}{|c|}{--} & \multicolumn{3}{|c|}{$-54.9^{v i}$} \\
\hline
\end{tabular}

' McIntyre, et al., 2002

ii Howells, et al., 2012, Table 2

iii See text.

iv Converted from corresponding nodal value using ratios found by Röper and Schwarz, 1989

$\checkmark$ Converted from corresponding flut/stin value using ratio used by Mclntyre, et al., 2002.

vi Calculated using $E_{x}$ equation and concentrations reported by Howells 2012

vii Converted from the corresponding motor value using ratio found in Howells, et al., 2012.

viii Howells, et al. 2012 indicates no difference between motor and sensory axons for this parameter 